DOI: https://doi.org/10.14311/TPFM.2021.003

\title{
LABYRINTH SEAL TOTAL TEMPERATURE INVESTIGATION
}

\author{
Michal Čížek ${ }^{1}$, Lukáš Popelka ${ }^{1}$, Tomáš Vampola ${ }^{1}$ \\ 1 Center of Aviation and Space Research, Faculty of Mechanical Engineering, Czech \\ Technical University in Prague, Jugoslávských partyzánů 1580/30, 16000, Prague
}

\begin{abstract}
This article presents the labyrinth seal thermal energy investigation in an aircraft turbine engine application. It starts by describing the CFD calculation with three critical radial clearance variants and three variants of the number of labyrinth seal teeth. The calculation result of the aircraft turbine engine boundary conditions is shown. The CFD, verification experiment and comparison with current labyrinth seal design are presented.
\end{abstract}

Keywords: Labyrinth seal, total temperature, verification experiment, CFD calculation

\section{Introduction}

This article deals with labyrinth seals that are used in aircraft turbine engines. Especially, it deals with the CFD analysis and CFD verification in a turbo-propeller engine. The CFD result is very important for the thermodynamic performance parameters of the engine.

The objective of this paper is to present a labyrinth seal CFD calculation and verification test comparison; as in current literature the labyrinth seal verification measurement with aircraft turbine engine boundary conditions is not included. The labyrinth seal is a standard part of a modern aircraft turbine engine or other reaction engines that use rotating parts - the system named the secondary air flow system [1]. The labyrinth seal is used to eliminate mass flow between the rotating part and the stator part and to decrease

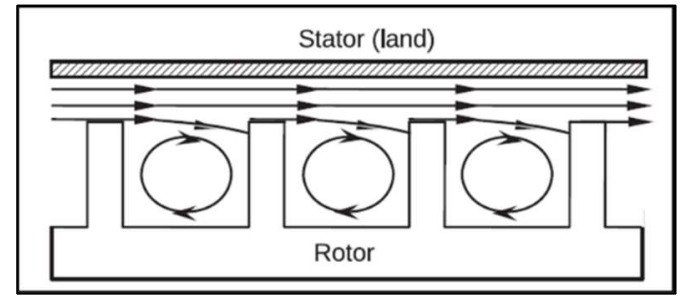

Figure 1: Labyrinth Seal Description - Teeth (in the Rotor) and Cavities between Teeth [2]

the pressure there [2]. The seal has an influence on the performance parameters (e.g. when the mass flow through the seal is high, the engine has a higher fuel consumption, etc.) see [3] or [4]. The labyrinth seal consists of labyrinth teeth and cavities between them (see Figure 1).

From the figure it is obvious that there is a fully developed swirl in the cavity between the teeth - [5]. The swirl helps to reduce the kinetic energy of the air flow. The initial research of the labyrinth seal was related to the steam turbine [6]. The differences between the steam turbine and aircraft turbine engines (or a gas turbine) are in the rotating shaft speed - it was discussed in [3] or [6] - in a steam turbine it is approx. $5000 \mathrm{~min}^{-1}$ and in an aircraft turbine engine it is approx. $35000 \mathrm{~min}^{-1}-$ see [7]. The specific air flow components (e.g., holes, gaps, taping) are used in the labyrinth seal - see [8]. Therefore, an important part of the labyrinth seal is the radial clearance $(\mathrm{RC})$. The radial clearance is the area between the top of the teeth and stator wall - see Figure 2.

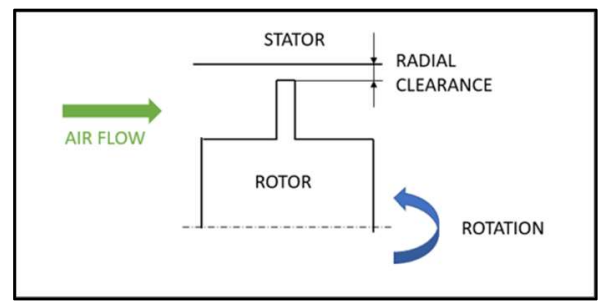

Figure 2: Radial Clearance and Labyrinth Seal Introduction 
The RC influences the operation of the engine or general labyrinth seal - see [9], because the RC regulates the mass flow through the seal - see [2]. The RC can be controlled by using abradable material on the stator wall. The abradable material is used in modern labyrinth seals - see [10]. The principle of the abradable material is that, when the machine is starting, the radial clearance is minimal. Based on the shaft vibration, the teeth create some rabbet in the abradable stator part. The rabbet has a specific setting for specific teeth. This article outlines other ways of controlling the RC.

In addition, the Computational Fluid Dynamics (CFD) is used in this research. The CFD is a way of calculating or predicting the behavior of the air flow in the machine. The two-dimensional (2D) CFD calculation was used in the first research of the labyrinth seal - [11] and [12]. The 2D CFD analyses are good for the preliminary design of the seal. With the growth of the computational capacity, the threedimensional (3D) CFD analysis is used more frequently The 3D approach is suitable for better understanding of the air flow with a developed swirl in the cavities in the labyrinth seals between the teeth. Some labyrinth seal preliminary 3D CFD research was published in [13], where the labyrinth seal with different rotating speed was analyzed. The labyrinth seal analysis with constant rotating speed was published in [9]. The rotating speed influence on the functionality of labyrinth seal and its measurement were published in [14]. An important chapter in the CFD calculation is its verification. The labyrinth seal CFD verification is possible in a real engine - like in [14]. However, it is possible to use the currently measured data presented in [15].

\section{3D CFD Calculation}

The labyrinth seal consists of rotating labyrinth teeth and cavities between the teeth (similar like in Figure 1). The general labyrinth seal CFD calculation was introduced in [15], where the four teeth calculation was presented. In this paper the five and six teeth CFD calculation are discussed. The calculation geometry

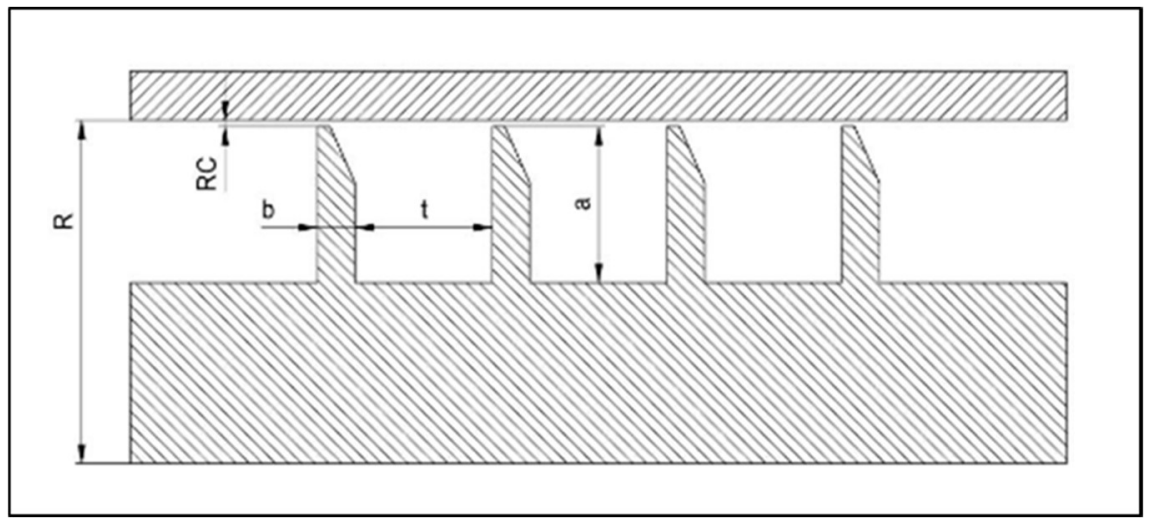

Figure 3: Geometry Description of RC, Length of Cavity, Width of Teeth and Height of Teeth consists of a rotating labyrinth seal domain, inlet domain and outlet domain. The inlet and outlet domains are nonrotating. All domains have a shape in the form of 5 degree conical volume. The calculation grid has 3.4 million of cells totally (i.e., in both domains). The grid $\mathrm{Y}+$ number is 0.69. The wall fitted grid was used in all domains for good calculation. In the RC, the maximum number of layers was 14 . The critical grid analysis is in [14]. A geometry description of the four teeth labyrinth seal can be found in Figure 3 and the values are in Table 1. The different number of $\mathrm{RC}$ was used in all calculations.

Table 1: Geometry Values of Length of Cavity, Width of Teeth and Height of Teeth

\begin{tabular}{|l|c|c|c|c|}
\hline Number of teeth & $\mathrm{R}[\mathrm{m}]$ & $\mathrm{a}[\mathrm{m}]$ & $\mathrm{b}[\mathrm{m}]$ & $\mathrm{t}[\mathrm{m}]$ \\
\hline All combinations & 0.089 & 0.0024 & 0.0057 & 0.0211 \\
\hline
\end{tabular}

For comparison, the nondimensional corrective $\mathrm{RC}$ named $\mathrm{RC}_{\mathrm{CORR}}$ was defined in (1):

$$
R C_{C O R R}=\frac{R C}{R C+}
$$

where the $\mathrm{RC}+$ is $\mathrm{RC}$ without the teeth. The variants of $\mathrm{RC}_{\mathrm{CORR}}$ are listed in Table 2.

Table 2: $\mathrm{RC}_{\mathrm{CORR}}$ Values

\begin{tabular}{|c|c|c|c|}
\hline $\mathrm{RC}_{\mathrm{CORR}}[-]$ & 0.02 & 0.04 & 0.06 \\
\hline
\end{tabular}

Four, five and six teeth variants were calculated with all $\mathrm{RC}_{\mathrm{CORR}}$ combinations. 
All calculations were carried out using the same pressure difference that corresponds to [7]. The same constant CFD calculation boundary conditions (see Figure 4) were set in both variants:

- Inlet total pressure of $660 \mathrm{kPa}$

- Inlet total temperature of $542 \mathrm{~K}$

- Outlet static pressure of $508 \mathrm{kPa}$

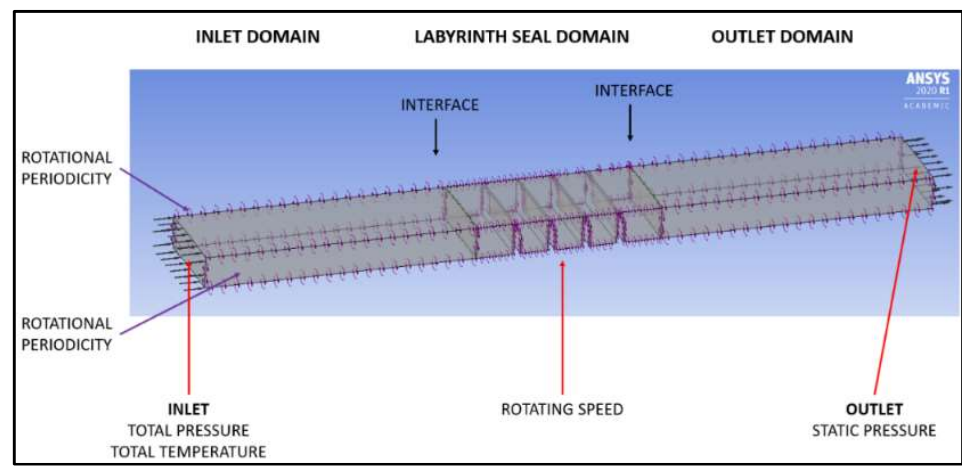

Figure 4: CFD Boundary Conditions

Two calculation setups were used:

1. Four, five and six teeth flow analysis with constant rotating speed

2. Four teeth flow analysis with different rotating speed

Based on the literature search ([5], [9] and [16]) the k- $\varepsilon$ turbulent model was used. The Total Energy heat transfer model and the air ideal gas as a fluid medium were used. The ANSYS CFX Solver with physical timescale control was used. The solver works on the basis of the Navier-Stokes equations. The thermodynamic parameters that are present in this paper are total temperature (2), total enthalpy (3) and kinetic energy (4). The labyrinth seal rotating speed is defined in (5). These parameters were chosen because they describe the thermodynamic phenomenom in the labyrinth seal and e.g., it is easy to measure the total temperature. The mass flow trendlines in the same labyrinth seal geometry are not included because they are described in [9]. The result from [9] is that the mass flow is decreasing with decreasing clearance.

$$
\begin{aligned}
T_{C C O R R} & =\frac{T_{C}}{T_{C V H}}, \\
h_{C C O R R} & =\frac{h_{C}}{h_{C V H}}, \\
E k_{C O R R} & =\frac{E k}{E k_{V H}}, \\
n_{C O R R} & =\frac{n}{n_{V H}},
\end{aligned}
$$

where the $\mathrm{VH}$ indexed parameters are the reference parameters that correspond to [7] where the typical average thermodynamic parameters correspond to a small turboprop aircraft engine

For the first result for the four teeth, where the thermodynamic parameters are plotted with a constant labyrinth seal rotating speed, see Figure 5. The second result for the five teeth is in Figure 6 . The third result for the six teeth is in Figure 7. The calculation can be considered stable after 1000 iterations. The values of residuals are in Table 3.

Table 3: Values of Residuals

\begin{tabular}{|c|c|}
\hline Residuum & Value \\
\hline RMS P-Mass & $1.0232 \mathrm{e}-05$ \\
\hline RMS U-Mom & $3.0247 \mathrm{e}-05$ \\
\hline RMS V-Mom & $5.2618 \mathrm{e}-05$ \\
\hline RMS W-Mom & $2.1262 \mathrm{e}-05$ \\
\hline RMS H-Energy & $1.4350 \mathrm{e}-04$ \\
\hline RMS E-Diss.K & $1.4524 \mathrm{e}-03$ \\
\hline RMS K-TurbKE & $2.7811 \mathrm{e}-04$ \\
\hline
\end{tabular}

From the constant labyrinth rotating speed calculation, it is clear that the total temperature increases with a higher number of teeth. The total temperature gradient in the last teeth is 0.195 , total enthalpy gradient is 0.216 and kinetic energy gradient is 0.128 with minimal $\mathrm{RC}_{\mathrm{CORR}}$ in the four teeth combination. With the five teeth combination, the total temperature gradient is 0.264 , total enthalpy gradient is 0.293 and kinetic energy gradient is 0.164 . With the six teeth combination, the total temperature gradient is 0.325 , 
total enthalpy gradient is 0.361 and kinetic energy gradient is 0.106 . Based on the same labyrinth seal rotating speed it can be seen that the kinetic energy gradient is the same, but the total temperature and total enthalpy are higher. As the next step, it would be interesting to analyze the labyrinth seal with a different rotating speed. The constant $\mathrm{RC}_{\mathrm{CORR}}=0.04$ and four teeth combination were selected for the calculation with nonconstant rotating speed.

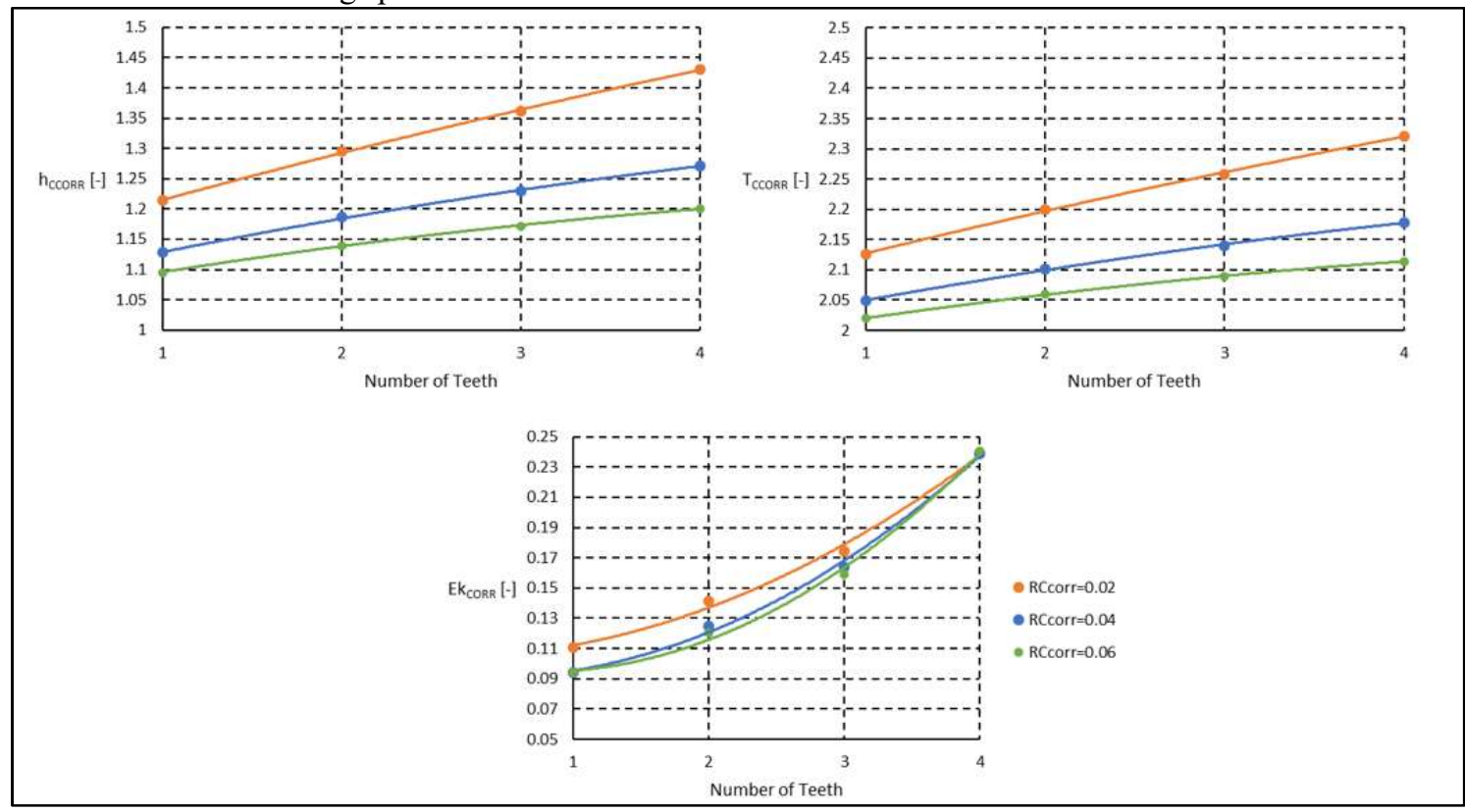

Figure 5: Four Teeth Constant Rotating Speed Result (hCORR - Top Left, $\mathrm{T}_{\mathrm{CCORR}}-$ Top Right and Ek $\mathrm{C}_{\mathrm{CORR}}$ - Down)

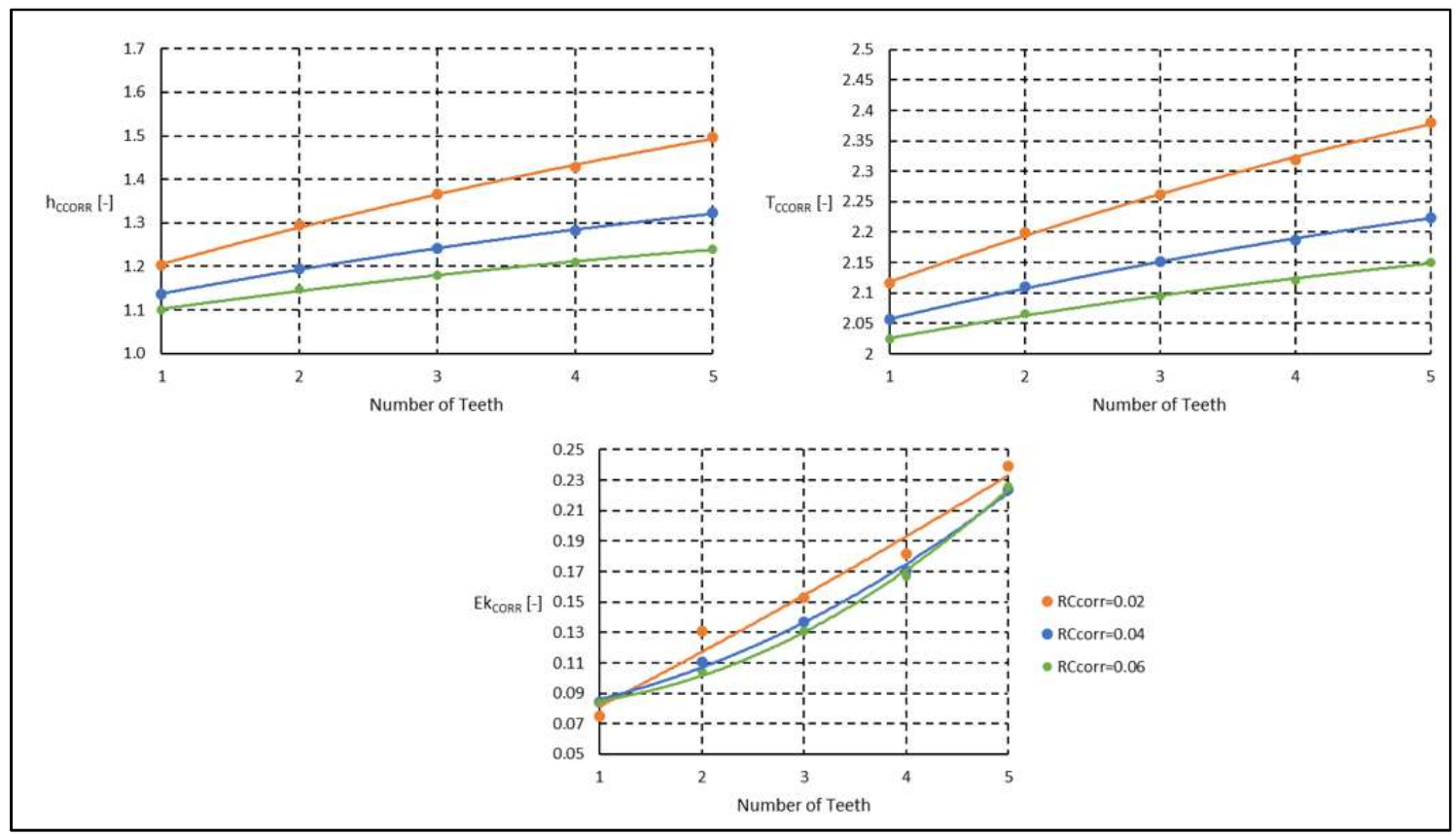

Figure 6: Five Teeth Constant Rotating Speed Result (hCORR - Top Left, $\mathrm{T}_{\mathrm{CCORR}}-$ Top Right and Ek $\mathrm{k}_{\mathrm{CORR}}$ - Down) 


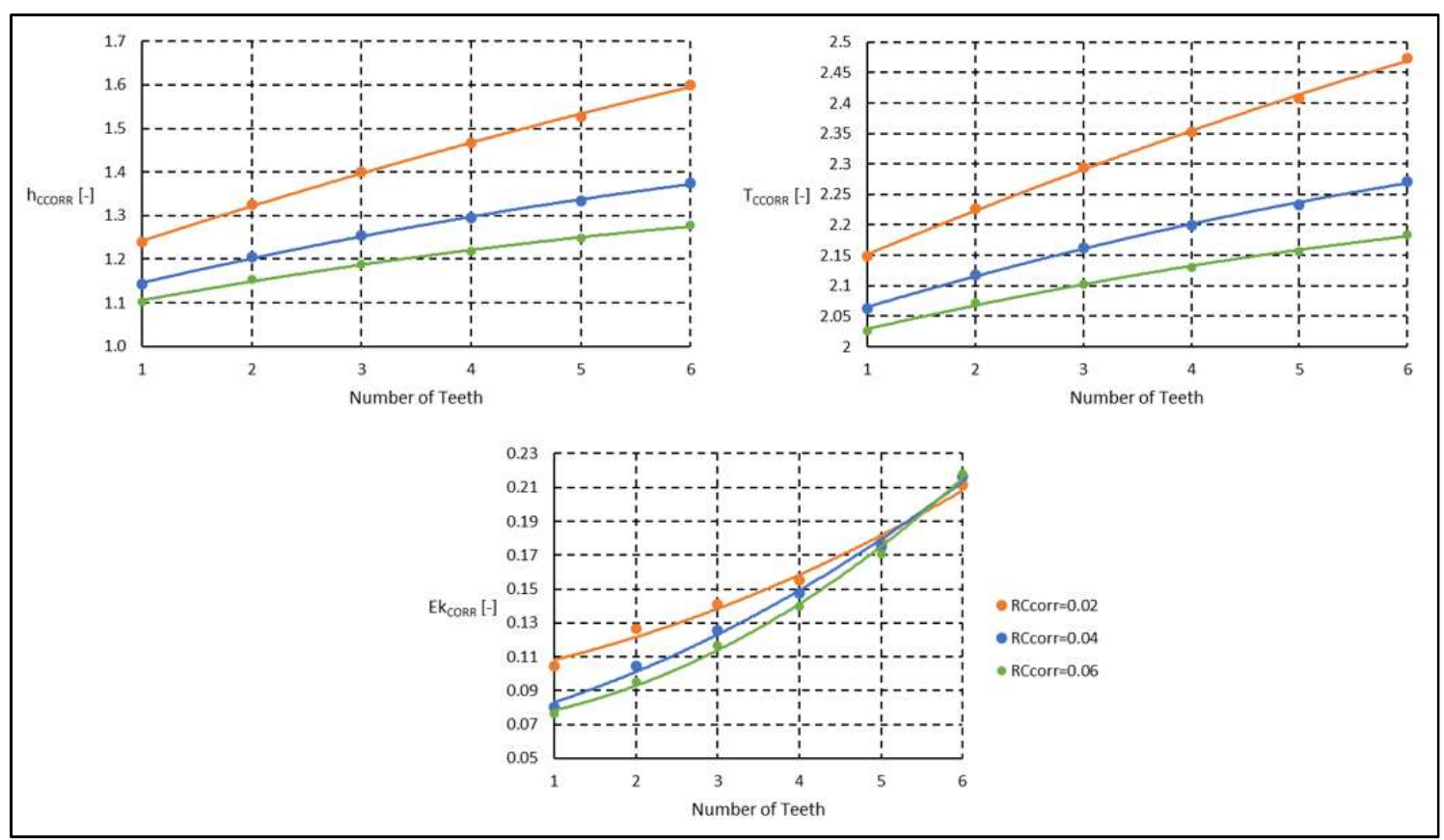

Figure 7: Six Teeth Constant Rotating Speed Result (hCORR - Top Left, $\mathrm{T}_{\mathrm{CCORR}}-$ Top Right and Ek $\mathrm{C}_{\mathrm{CORR}}$ Down)

The nonconstant rotating speed (i.e., steady simulations with a different rotating speed) setup is in Table 4 . Table 4: Nonconstant Rotating Speed Calculation Setup

\begin{tabular}{|c|c|}
\hline & n CORR [-] \\
\hline \multirow{4}{*}{$\begin{array}{c}\text { Nonconstant rotating } \\
\text { speed }\end{array}$} & 0.136 \\
\cline { 2 - 2 } & 0.191 \\
\cline { 2 - 2 } & 0.273 \\
\cline { 2 - 2 } & 0.546 \\
\cline { 2 - 2 } & 0.818 \\
\cline { 2 - 2 } & 1 \\
\cline { 2 - 2 } & 1.227 \\
\cline { 2 - 2 } & 1.364 \\
\hline
\end{tabular}

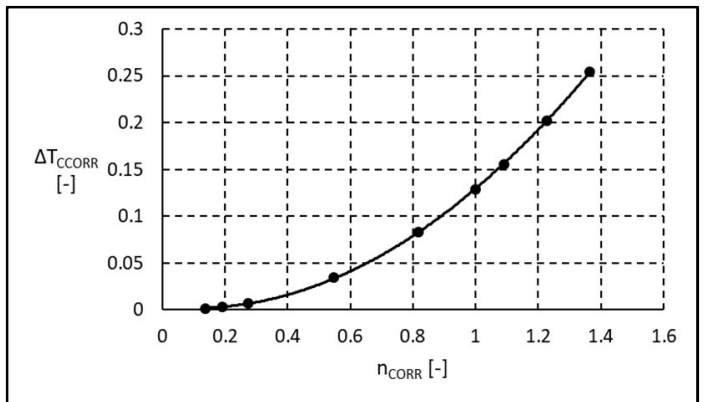

Figure 8: Total Temperature Gradient with Nonconstant Rotating Speed

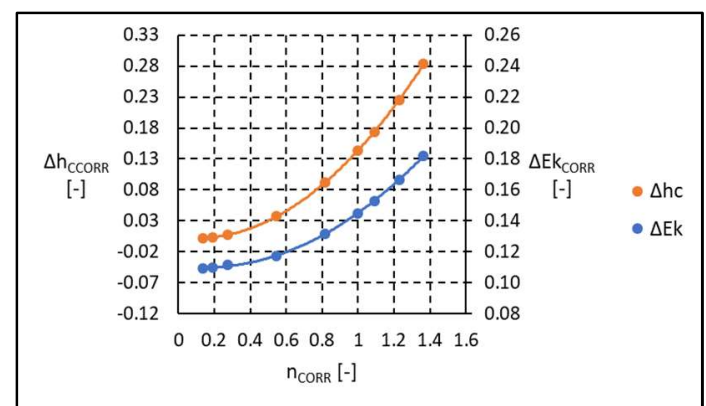

Figure 9: Total Enthalpy and Kinetic Energy Gradients with Nonconstant Rotating Speed

The total temperature, total enthalpy and kinetic energy gradients are in Figure 8 and Figure 9. The gradient is the value between the last and the first tooth. In the maximum nonrotating labyrinth seal speed $\left(\mathrm{n}_{\mathrm{CORR}}=1.364\right)$ the total temperature gradient is 0.255 , total enthalpy gradient is 0.283 and kinetic energy gradient is 0.182 . This trend corresponds to the result presented in [15]. The total temperature and total enthalpy distribution with a different rotating speed are in Figure 10 and Figure 11. Based on this 
knowledge, it is possible to validate the calculated data with a verification experiment. The experiment must correspond to the boundary conditions calculation. For a better engine performance, the lowest possible temperature is used [3].

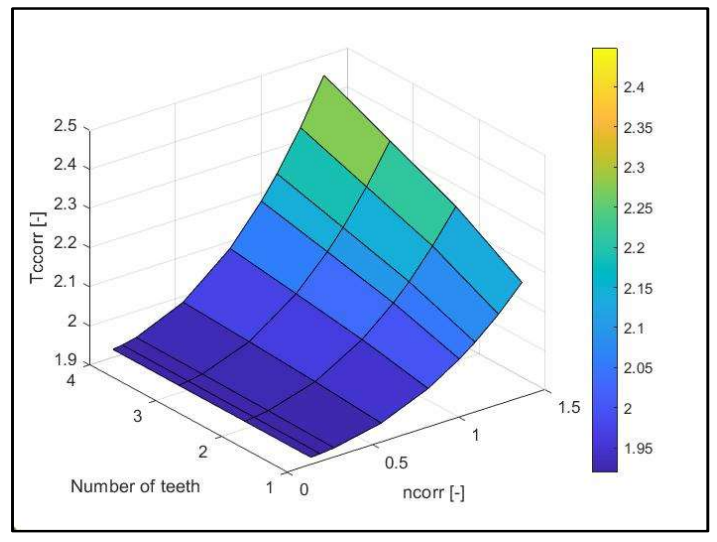

Figure 10: Total Temperature Distribution

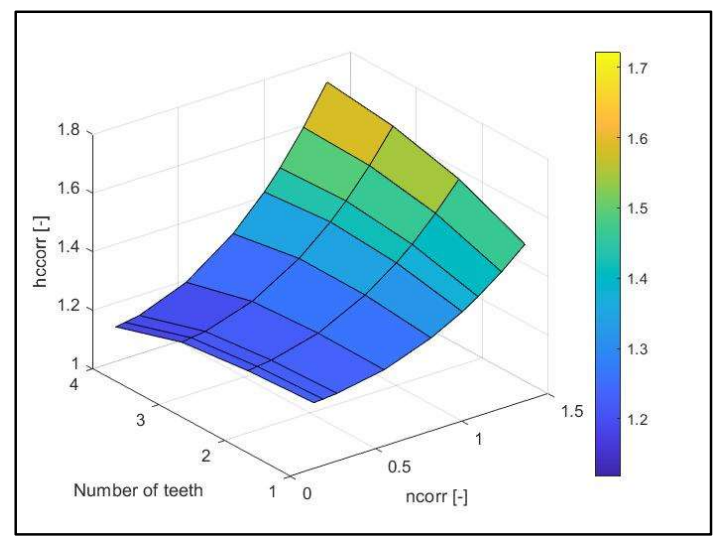

Figure 11: Total Enthalpy Distribution

\section{Verification Experiment}

The Center of Aviation and Space Research has a four teeth labyrinth seal measurement data from real

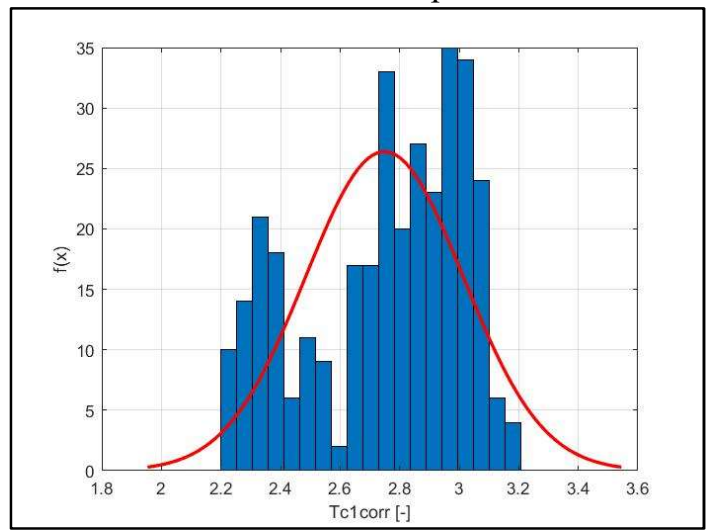

Figure 12: $\mathrm{T}_{\mathrm{C} 1 \mathrm{CORR}}$ Gaussian distribution

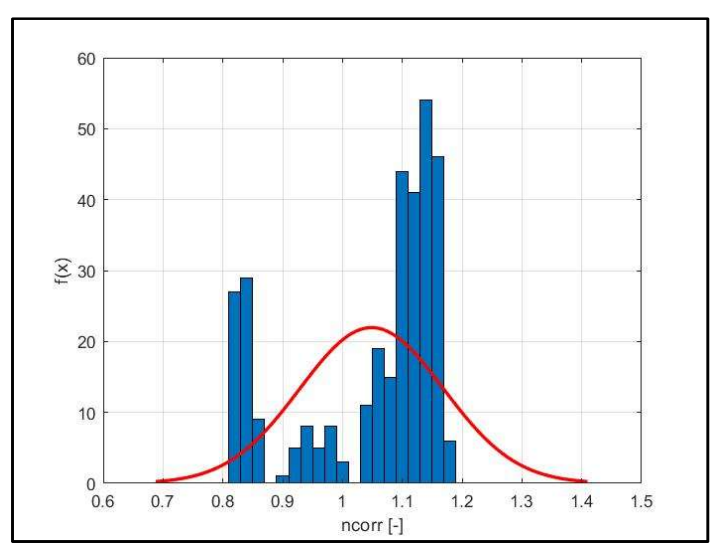

Figure 14: $\mathrm{n}_{\mathrm{CORR}}$ Gaussian Distribution

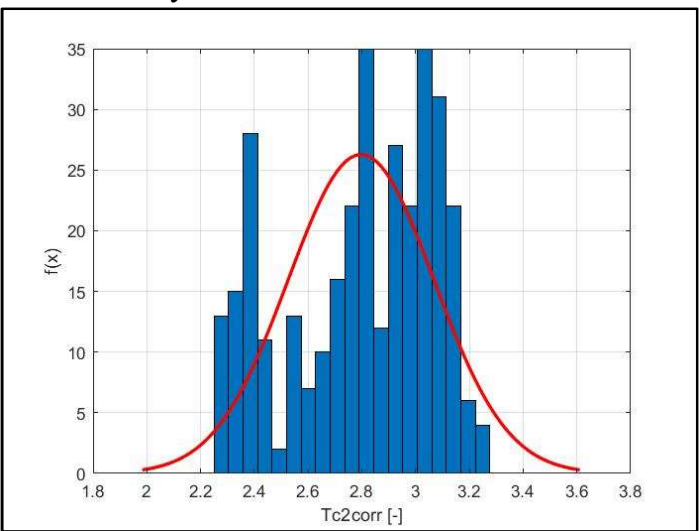

Figure 13: $\mathrm{T}_{\mathrm{C} 2 \mathrm{CORR}}$ Gaussian Distribution

turboprop engine measurements. The total temperature labyrinth seal inlet (named $\mathrm{T}_{\mathrm{ClCORR}}$ ) and outlet (named $\mathrm{T}_{\mathrm{C} 2 \mathrm{CORR}}$ ) total temperature and rotating speed were measured. In the test, 338 steady state (i.e., $180 \mathrm{~s}$ stabilization) points were measured. The type $\mathrm{K}$ thermocouple was used and their accuracy was $\pm 2.2 \mathrm{~K}$. Based on the [17], the Gaussian distribution functions of measured parameters were calculated. Based on (2), the total temperatures were calculated. The labyrinth seal rotating speed was calculated by (5). The Gaussian distribution of both temperatures is in Figure 12 and Figure 13. All total temperatures data are inside the three standard deviations, thus it is possible to exclude the significant error [17]. The same situation is with the rotating speed - see Figure 14. It is possible to say that the measured data and their accuracy can be used for a CFD calculation evaluation. 
To start, the raw data were plotted. In Figure 15 the rotating speed is in the $\mathrm{x}$ axis, absolute values of total temperature are in the primary $\mathrm{y}$ axis and their gradient is in the secondary $\mathrm{y}$ axis. For a better comparison with the calculated data, the raw experimental data were interpolated by a $2^{\text {nd }}$ degree polynomial function.

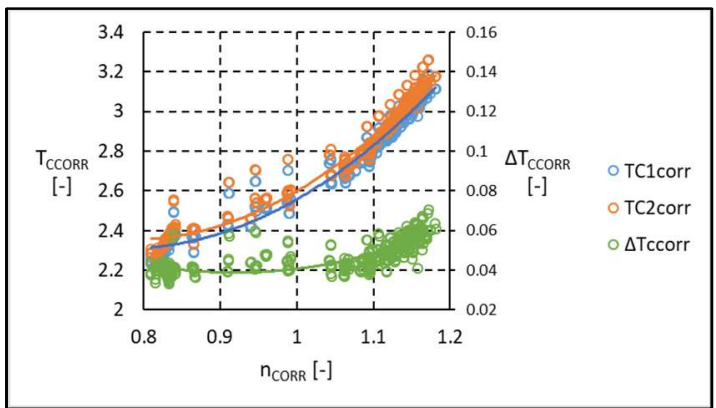

Figure 15: Experimental Raw Data

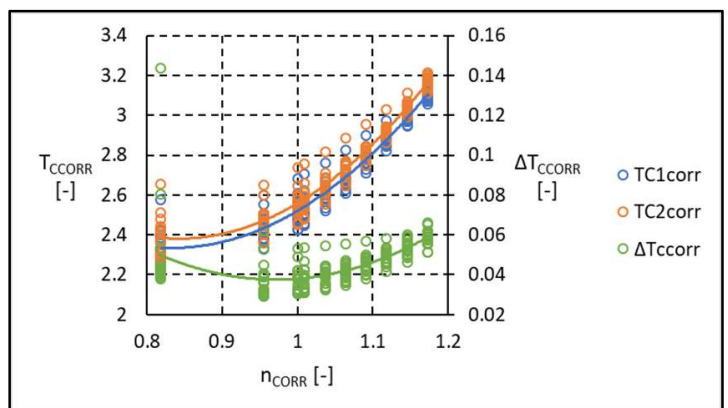

Figure 16: Interpolated Data

The resulting values at 10 nondimensional rotating speeds shown in Figure 16 were recalculated.

Three labyrinth seal rotating speeds were selected for the CFD comparison, listed in Table 5. The absolute values in Table 5 are different. It is due to the fact that in the CFD simulations all of the domains are isolated. There is no heat transfer to the other domain (e.g. the steel stator part etc.). As the experiment is in the real turboprop engine, there is a heat transfer to other parts of the engine. However, other (i.e., the same pressure difference) experiment boundary conditions are the same.

Table 5: Experiment and CFD Comparison

\begin{tabular}{|c|c|c|}
\hline nCORR [-] & $\boldsymbol{\Delta} \mathbf{T}_{\text {CCORR }}-\mathbf{C F D}[-]$ & $\boldsymbol{\Delta}_{\text {CCORR }}-$ Experiment $[-]$ \\
\hline 0.81 & 0.083 & 0.049 \\
\hline 1 & 0.123 & 0.038 \\
\hline 1.09 & 0.156 & 0.045 \\
\hline
\end{tabular}

\section{Results and discussion}

This paper describes the air flow in the labyrinth seal of an aircraft turbine engine application. For the validation of the CFD calculation, the labyrinth seal verification experiment was set up. In the CFD calculation, the total temperature gradient in the labyrinth seal was detected. The CFD calculations were divided into calculations with constant and nonconstant rotating labyrinth seal speed. The three variants of $\mathrm{RC}_{\mathrm{CORR}}$ and the number of teeth were used in the constant rotating speed calculation. The preliminary result of this calculation is that the total temperature and enthalpy were increased, although in literature it is shown that the total temperature must be a constant value ([2] and [6]). Based on this calculation, the nonconstant labyrinth seal rotating speed calculation was performed. The result from the nonconstant speed calculation is that the higher total temperature, the higher the rotating speed.

The CFD data were validated by a labyrinth seal measurement in a real turboprop engine. The experimental labyrinth seal consists of four teeth and a constant $\mathrm{RC}_{\mathrm{COR}}$. The comparison between the CFD calculation and the experiment is in Table 5. The absolute values of total temperature gradient are different, but the real difference is not so significant and corresponds to the standard practice used in aviation and the data are acceptable. The differences between the CFD and the experiment are due to the fact that the CFD calculations are in isolated domains. In the CFD simulations, there is only mechanical work (i.e., rotating speed) in the seal. In a real turboprop engine - which was used for the comparison - there is heat transfer to the other parts of the engine. However, the experiment confirmed the fact that the total temperature increased with increasing rotating speed and shows increasing trendlines. In further work, it will be necessary to deal with measurements that could simulate the boundary conditions of the CFD calculation more accurately.

From the CFD calculation, it is clear that the radial clearance is a critical parameter. The way to increases the engine performance parameters is to control the radial clearance during the life cycle of the engine. Technically, it should be possible to split the nonrotating stator part to smaller parts that would correspond to solid iris diaphragms [18]. 


\section{Acknowledgment}

Authors acknowledge support from the ESIF, EU Operational Programme Research, Development and Education, and from the Center of Advanced Aerospace Technology (CZ.02.1.01/0.0/0.0/16_019/0000826), Faculty of Mechanical Engineering, Czech Technical University in Prague.

\section{References}

[1] Han Je-Chin, Dutta Sandip, Ekkad Srinath: Gas Turbine, Heat Transfer and Cooling Technology. CRC Press, ISBN: 978-1-4665-6490-9, (2013) pp. 1-26

[2] Sultanian Bijay K.: Gas turbine: Internal flow systems modelling, Cambridge University Press, ISBN: 978-110-7170-094: (2018) pp. 237-256

[3] Kurzke J., Halliwell I.: Propulsion and Power, Springer Internationaly Publishing, ISBN: 978-3319-75977-7: (2018) pp. 687-696

[4] Chupp Ramymond, Hendrics Robert, Lattime Scott, Steinetz Bruce: Sealing in turbomachinery, NASA/TM-2006-214341: (2006)

[5] Ilieva Galina, Pirovsky Christo: Labyrinth seals with application to turbomachinery. Materials Science \& Engineering Technology, vol. 50, no. 5: (2019) pp. 479-491

[6] Ščeglajev Andrej Vladimirovič: Parní turbíny, Státní nakladatelství technické literatury, (1983) pp. 229-242

[7] Type certificate EASA, www.easa.europa.eu/sites/default/files/dfu/EASA\%20TCDS\%20E.070\%20issue\%208.pdf

[8] Zimmermann Hubert: Some Aerodynamic Aspects of Engine Secondary Air Systems. ASME 1989 International Gas Turbine and Aeroengine Congress and Exposition, vol. 1: (1989), ISBN: 978-07918-7913-9

[9] Č́žžek Michal, Pátek Zdeněk: On CFD Investigation of Radial Clearance of Labyrinth Seals of a Turbine Engine. Acta Polytechnica, vol. 60, no. 1: (2020) pp. 38-48, 2020

[10] Childs Dara, Weatherwax Mark: Theory Versus Experiment for the Rotordynamic Characteristics of a High Pressure Honeycomb Annular Gas Seal at Eccentric Positions. Journal of Tribology, vol. 125, no. 2: (2003) pp. 422-429

[11] Eser Dursun, Kazakia Jacob Y.: Air flow in cavities of labyrinth seals. International Journal of Engineering Science, vol. 33, no. 15: (1995) pp. 2309-2326

[12] Furst Jiří: Numerical simulation of flows through Labyrinth seals, Applied Mechanics and Materials, vol. 821: (2015) pp. 16-21

[13] Č́žžek Michal, Pátek Zdeněk, Vampola Tomáš: Aircraft Turbine Engine Labyrinth Seal CFD Sensitive Analysis. Aerospace Science and Engineering, vol. 10, no. 19: (2020) pp. 6830

[14] Č́ižek Michal, Vampola Tomáš: Labyrinth Seal of Aircraft Turbine Engine Air Flow Calculation at High Viskosity. Acta Mechanica Slovaca, vol. 23, no. 4: (2020) pp. 6-12

[15] Č́žžek Michal, Vampola Tomáš, Popelka Lukáš: Comparison of Labyrinth Seal Calculation and Real Aircraft Turbine Engine Measuremen. Topical Problem of Fluid Mechanics 2020, (2020) pp. 19-26

[16] Tong Seop Kim, Kyu Sang Cha: Comparative analysis of the influence of labyrinth seal configuration on leakage behaviour. Journal of Mechanical Science and Technology, vol. 23, no. 10: (2009) pp. 2830-2838

[17] Hughes Ifan G., Hase Thomas P.A.: Measurements and their Uncertainties: A practical guide to modern error analysis, Oxford University Press, ISBN: 978-0-19-956632-7: (2010) pp. 23-34

[18] Clay Reginald S.: Solid Iris Diaphragms. Journal of Scientific Instruments, vol. 18, no. 9: (1941) pp. 190-191 